\title{
Validação de um modelo teórico usado no cuidado da família que tem um filho com cardiopatia
}

\author{
VALIDATION OF A THEORETICAL MODEL APPLIED ON THE CARE \\ OF FAMILIES WITH A CHILD WITH CARDIOPATHY
}

\section{VALIDACIÓN DE UN MODELO TEÓRICO USADO EN EL CUIDADO DE LA FAMILIA CON UN HIJO CON CARDIOPATIA}

Yelma Jacob', Regina Szylit Bousso²

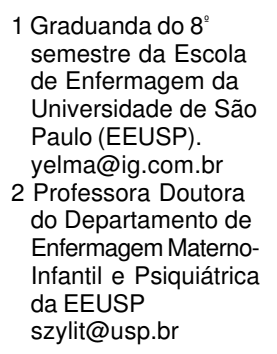

Graduanda do $8^{\circ}$ Escola de Enfermagem da Universidade de São (EEUSP). Professora Doutora Enfermagem Maternoszylit@usp.br

\section{RESUMO}

Validar o modelo teórico "Buscando preservar a integridade da unidade familiar"; aplicando-o à situação da família que vivencia a situação. A coleta de dados decorreu por meio de entrevistas com seis familiares que vivenciaram a experiência de ter um filho que sofreu uma intervenção cirúrgica cardíaca, cujas perguntas foram pautadas no referido modelo, tendo como foco a experiência familiar, durante o tempo da cirurgia cardíaca. Os dados gerados foram analisados de acordo com a Teoria Fundamentada nos Dados. Pela análise comparativa dos resultados dos dois estudos, foi possível validar o modelo teórico para a experiência da família que vivencia a cirurgia cardíaca do filho. Em função da natureza específica da experiência, dois novos temas emergiram: vivendo uma experiência solitária e tendo superado uma etapa, ampliando o modelo teórico original.

\section{ABSTRACT}

This article is based on a survey aimed at validating the theoretical model "Trying to preserve the integrity of the family unit" by applying it to the situation of families living through the experience of having a child undergoing heart surgery. Data was collected through interviews with six family members who had gone through that experience. The questions were laid out according to the model, focusing on the family experience during the time of heart surgery. The data was analyzed according to the Grounded Theory. Results showed that it is possible to validate the theoretical model for the experience of families who had a child undergoing heart surgery through the comparative analysis of the results of both studies. Because of the specific nature of the experience, two new themes emerged: living a lonely experience and overcoming a phase, thus widening the original theoretical model.

\section{KEY WORDS}

\section{DESCRITORES}

Validade/métodos.

Relações familiares.

Atitude frente a saúde.

Procedimentos cirúrgicos cardiovasculares.
Validity/methods.

Family relations.

Attitude to health.

Cardiovascular surgery procedures.

\section{RESUMEN}

Validar el modelo teórico "Buscando preservar la integridad de la unidad familiar"; aplicándolo a la situación de la familia que vivencia la situación de cirugía cardiaca de un hijo. La recolección de datos se llevó a cabo por medio de entrevistas a seis familiares que vivenciaron la experiencia de tener un hijo que sofrió una intervención quirúrgica cardiaca, cuyas preguntas fueron basadas en el referido modelo, teniendo como foco la experiencia familiar, durante el tiempo de la cirugía cardiaca. Los datos generados fueron analizados de acuerdo con la Teoría Fundamentada en los Datos. Resultados - Por el análisis comparativo de los resultados de los dos estudios, fue posible validar el modelo teórico para la experiencia de la familia que vivencia la cirugía cardiaca del hijo. En función de la naturaleza específica de la experiencia, emergieron dos nuevos temas: viviendo una experiencia solitaria y habiendo superado una etapa, ampliando así el modelo teórico original.

\section{DESCRIPTORES}

Validez/método.

Relaciones familiares.

Actitud frente a la salud.

Procedimientos quirúrgicos cardiovasculares. 


\section{INTRODUÇÃO}

No processo saúde-doença, a experiência da família tem sido nosso objeto de estudo, como parte dos trabalhos do Grupo de Estudos de Enfermagem da Família (GEENF), no sentido de compreender as demandas e criar estratégias para o cuidado da família.

A pessoa e sua doença não são mais os principais focos de atenção do enfermeiro, mas também, a família é vista como foco dessa atenção. A assistência centrada na criança e na família é ainda algo bastante incipiente em nosso contexto, passando pelo âmbito da motivação pessoal. O fato pode ser comprovado no trabalho realizado em uma instituição que se apresenta com uma filosofia humanística para o cuidar, que contempla, em sua documentação de sistematização do cuidar, diretrizes que apontam para o cuidado da família. As autoras identificaram incoerência entre estes elementos e o pensar e agir de alguns profissionais de enfermagem ${ }^{(1)}$.

A mudança na ênfase para a família como um domínio emergente na enfermagem é ainda muito tímida, devendo ser fortalecida por intermédio da realização de estudos, possibilitando, posteriormente, a assistência da enfermeira ${ }^{(2)}$.

Este panorama reflete a necessidade de estudos referentes aos aspectos da experiência da família ao vivenciar uma situação de doença. Neste sentido, entendemos que o enfermeiro ao conhecer os aspectos da experiência da família estará mais instrumentalizado para o cuidado.

Em um estudo realizado com famílias que tinham o filho internado com cardiopatia congênita, pudemos conhecer o processo vivido pela família durante a fase pré-operatória. Este estudo mostrou que o dia da cirurgia é muito aguardado pelos pais. A família teme complicações que possam ocorrer na cirurgia, principalmente, a morte da criança ${ }^{(3)}$. Outra evidência deste estudo emergiu durante a fase da coleta dos dados da referida pesquisa ${ }^{(3)}$, quando foi possível perceber o desespero dos pais quando entregavam seus filhos no Centro-Cirúrgico. Muitas vezes, a mãe encontrava-se sozinha, pois a família havia ficado na cidade de origem.

No estudo realizado sobre o impacto do diagnóstico para os pais da criança portadora de cardiopatia congênita foi possível compreender que uma das dificuldades vivenciadas pela família na fase de conhecimento do diagnóstico é precisar conviver, ao mesmo tempo, com a esperança de cura e a possibilidade de morte da criança durante a cirurgia ${ }^{(4)}$.

Em um amplo estudo realizado com famílias que vivenciam a experiência de ter um filho internado em UTI pediátrica, propõe-se um modelo teórico explicativo da experiência da família ${ }^{(5)}$. O modelo integra os componentes relacionados às causas e às consequiências vivenciadas pela família com o filho internado na UTI a partir de dois fenômenos que compõem esta experiência. O primeiro fenômeno tendo uma ruptura familiar, representa a ruptura familiar decorrente da internação da criança em UTI pediátrica, caracterizada pela separação da criança do resto da família, o que deixa a família em ruínas. O segundo fenômeno: vivendo a possibilidade de vir a perder o filho mostra o movimento da família, para resguardar o grupo familiar de uma cisão definitiva, face à situação ameaçadora e instável de ter um filho internado em UTI pediátrica.

Segundo a autora

diante do ambiente da UTI, a família é confrontada com incertezas. A possibilidade da morte da criança causa um impacto enorme nas relações familiares. $A$ fronteira ambígua entre a vida e a morte traz um pânico intenso acerca de uma possível piora da criança. A família sofre com cada marco da experiência. Cada encontro com a criança, com os médicos, traz apreensão, deixando-a vivendo esperas apreensivas diante da expectativa que vive frente às incertezas e tomada pela imobilização diante das barreiras com que se depara(5).

Vivendo a possibilidade de vir a perder o filho é a conseqüência do processo vivido pela família. O modelo teórico descrito tem na categoria central Buscando preservar a integridade da unidade familiar, o elemento capaz de integrar os componentes relacionados às causas e às conseqüências vivenciadas pela família com o filho internado na UTI.

Neste sentido, e de acordo com Morse ${ }^{(6)}$, pensamos que o modelo teórico Buscando preservar a integridade da unidade familiar, proposto por Bousso ${ }^{(5)}$, pode ser um referencial teórico para o desenvolvimento de novos estudos, no sentido de ampliar ou aprofundar questões relacionadas à experiência da família.

A partir da afirmação apresentada no modelo teórico ${ }^{(5)}$ de que a família com o filho na UTI vivencia: (1) uma ruptura familiar quando a criança é internada e (2) vivencia a possibilidade de vir a perder o filho e, pensando na situação específica da família que entrega o filho para uma cirurgia cardíaca, questionamos:

- É possível aplicar o processo Vivendo a possibilidade de vir a perder o filho, à família que vive a experiência de aguardar a cirurgia do filho?

- A separação da criança e família quando esta entrega o filho para realização de uma cirurgia cardíaca, é diferente daquela quando deixa o filho aos cuidados da equipe da UTI?

\section{OBJETIVO}

Refletindo sobre os referidos trabalhos que ressaltam a importância da necessidade de orientações à família, 
utilizando-se dos mais diversos recursos, relembrando o desespero daquelas famílias que precisam separar-se do filho, entregando-o às mãos da equipe do centro cirúrgico sem a certeza de que a criança conseguirá sobreviver à cirurgia e pensando na possibilidade do emprego de um modelo teórico que sirva de instrumento para compreensão e atendimento das necessidades da família durante o tempo de cirurgia cardíaca, quando esta teme a morte do filho, estabelecemos o seguinte objetivo para este estudo:

- Validar o modelo teórico Buscando preservar a integridade da unidade familiar, quanto ao aspecto da família vivenciando a possibilidade de vir a perder o filho, com famílias que vivenciam a cirurgia cardíaca do filho.

\section{METODOLOGIA}

Ao se apresentar uma teoria, é possível utilizar métodos de pesquisa para realizar sua validação. O método tem como objetivo apurar o quão refinado a teoria descreve um fenômeno e suas relações ${ }^{(7)}$. Os passos metodológicos para validação de teoria consistem em: (1) definição das novas condições e variáveis para o estudo, (2) elaboração de instrumentos e definição do procedimento para a coleta dos dados, (3) verificação da aceitação da teoria utilizada como referencial, (4) coleta dos dados e (5) análise dos dados coerente com o método utilizado no primeiro estudo ${ }^{(7)}$.

Conforme já mencionamos, as condições e variáveis para este estudo foram definidas com famílias que vivenciam a experiência de ter um filho submetido à cirurgia cardíaca.

Os dados foram coletados através de entrevista. Elaboramos um roteiro que eliciasse sentimentos, pensamentos e experiências da família de forma que possibilitasse a obtenção de respostas para se atingir o objetivo proposto. Conforme sugere Morse ${ }^{(6)}$, as perguntas foram pautadas no referido modelo teórico, tendo como foco a experiência familiar, durante o tempo da cirurgia cardíaca.

As questões norteadoras foram:

Onde você ficou durante o tempo que seu filho estava em cirurgia?

Com quem você ficou?

Quem você gostaria que tivesse ficado com você?

O que passou pela sua cabeça durante esse período?

Que perguntas você se fez?

O que ajudou passar o tempo?

O que foi mais difícil durante esse período?

Como você se vê dentro do contexto exposto Buscando Preservar a integridade da unidade familiar?
Além deste roteiro, tivemos o cuidado de iniciarmos as entrevistas apresentando o diagrama do modelo teórico Buscando Preservar a integridade da unidade familiar ${ }^{(14)}$ fazendo as elucidações que se fizessem necessárias para o entendimento e verificando se ele seria aceito pelos participantes.

Participaram do estudo seis familiares (dois pais e quatro mães) que compunham cinco famílias e que vivenciaram a experiência de ter um filho que sofreu uma intervenção cirúrgica cardíaca, há pelo menos 48 horas. A idade dos familiares variou entre 23 e 55 anos e os diagnósticos das crianças eram variados.

A autorização para os procedimentos da coleta de dados foi solicitada ao Comitê de Ética da Escola de Enfermagem da USP e do hospital onde foi realizada a coleta. Após os devidos esclarecimentos e havendo concordância, solicitamos a assinatura do Termo de Consentimento Livre e Esclarecido (TCLE).

Na pesquisa de validação de teoria o método deve ser consistente com o método utilizado na pesquisa que gerou a teoria $^{(7)}$. Assim, para a codificação e categorização dos dados, utilizamos como base a Teoria Fundamentada nos Dados.

A análise dos dados ocorreu, simultaneamente, à coleta dos mesmos, realizando-se a codificação aberta e sua categorização, visando encontrar temas e categorias explicativas da experiência da família que vivencia o período trans-operatório da cirurgia cardíaca do filho na sala de espera ${ }^{(8)}$.

\section{RESULTADOS}

A análise das entrevistas permitiu identificar temas e categorias que descrevem o significado da experiência vivida pela família da criança que sofreu uma cirurgia cardíaca que é caracterizada por um movimento de sentimentos, pensamentos e ações da família, especialmente da mãe, que é quem geralmente acompanha a criança durante o processo da doença, incluindo o momento da cirurgia.

Este movimento é iniciado na família a partir do momento que esta recebe a informação que o filho tem um problema no coração nem sempre já com um diagnóstico definido, o que desperta uma nova preocupação com a criança. Esta experiência é explicada por meio de dois grandes temas: Decidindo pela cirurgia e Vivendo uma experiência solitária.

\section{Decidindo pela cirurgia}

É o primeiro tema composto por categorias que revelam a experiência da família desde o momento que recebe o diagnóstico até quando se decide pela cirurgia. Assim, Decidindo pela cirurgia, é toda a movimentação e envolvimento familiar no sentido de oferecer o melhor trata- 
mento para salvar a vida da criança. Esta decisão, muitas vezes, implica precisar buscar recursos em outras cidades, provocando uma ruptura da organização familiar, visto que, nesta decisão, a mãe permanece sempre ao lado da criança doente, para atendê-la no que precisar. A família avalia alternativas, faz escolhas, toma decisões, mobiliza os recursos pessoais e materiais de que dispõe e, quando possível, providencia antecipadamente planos de saúde e outros recursos que poderão acionar frente a uma nova dificuldade.

O médico falou que ia precisar, né? Aí eu e o pai dele decidimos. Ele até ficou meio assim, né... de não querer fazer, mas vimos que era o melhor para ele. Era um risco que tínhamos que correr juntos. Aí decidimos pela cirurgia. A gente sabia que aqui era o melhor lugar, não tinha mais onde procurar.

Decidindo pela cirurgia é melhor representado pelas categorias que retratam os sentimentos, comportamentos e decisões familiares.

A família é informada de que a criança apresenta um problema no coração nos primeiros dias após o nascimento e, assim, inicia-se o processo de ir sofrendo o impacto da doença da criança que aparece como uma surpresa. Os familiares não passam por uma fase de suspeita de alguma doença, na qual a criança tem sintomas, mas, simplesmente, recebem um diagnóstico de que o filho não é normal. Ainda que a família não saiba exatamente o diagnóstico, percebe que a criança tem alguma má formação ou problema no coração. Quando se constata a doença, a família vê-se às voltas com a procura de atendimento médico adequado, diante da perspectiva da perda do bebê recém-chegado. Descobrir que a criança é portadora de uma cardiopatia é o primeiro momento da experiência familiar, que vai desencadear todo o processo de decidir o tratamento.

Depois que eu soube que ele tinha problema no coração, aí me incentivaram para que eu procurasse aqui, este hospital. Procurei e cheguei aqui; eu tive ótimo atendimento pro meu filho.

Eu sempre esperei por uma criança normal então, quando ele nasceu bom...! Nós ficamos um pouco nervosos. Foi uma surpresa. Nunca ninguém na nossa família tinha tido algum problema de coração. Desde que ela nasceu, corro atrás da saúde dela.

A identificação da doença pela família está relacionada às alterações físicas que é capaz de observar na criança. Assustando-se com a situação da criança conforme identifica que a criança não é normal, percebendo sinais e sintomas da doença e vendo o sofrimento do filho, é o estímulo da família para a busca do tratamento. Com o desejo de ter um filho normal, a família manifesta sua vontade de tratar a criança a qualquer custo, tomando decisões para o melhor tratamento, mesmo que para isso seja preciso um sacrifício coletivo da família.
Que ele era roxinho... agora tá mais branco do que eu imaginava.

Não podia correr que cansava... dava até pena..

Assim, começa a existir um movimento coletivo com o objetivo de preservar a vida da criança, na qual, geralmente, aparece a mãe direcionando as decisões familiares. A partir do momento em que a família, com a ajuda dos parentes e amigos, organiza-se a fim de levar a criança para ser tratada em outra cidade, fica consolidada uma ordem de comando da mãe em relação às decisões e ações relacionadas à criança, à doença e à sua família. Para a família, a mãe é a pessoa mais capaz de decidir e cuidar da criança. Todos se sentem seguros, dessa maneira.

Eu direciono as decisões. As decisões são tomadas por mim... eu tenho que pesar porque, se eu falar: Vai lá, pega a J. ele vai e pega.

Aí, eu falei, vou para São Paulo com ele e você fica aqui com a casa e com o R. Porque ele ficando lá, minha mãe pode ajudar. Não dava para vir os três.

Este processo tem como fator interveniente o fato de que, muitas vezes, a família não reside em São Paulo e não encontra meios para tratar o filho na cidade em que reside, sendo orientada a procurar recursos em outro local. Este momento da experiência mostra uma ruptura familiar que vai além da separação da criança do convívio familiar, sendo melhor representada pela decisão da família, elegendo a mãe como responsável para acompanhar o tratamento da criança. Afastando-se fisicamente da família, implica, muitas vezes, sair de casa com o filho doente, sem destino certo, trajetória essa permeada por muito sofrimento e incertezas para todos da família.

Nesta busca por estratégias para lidar com a separação física imposta pela decisão do tratamento, o contato telefônico é a forma que os pais encontram para manterem-se mais próximos dos outros filhos, garantindo uma interação ainda que mínima. Eles realizam ligações telefônicas procurando não só obter e dar notícias, mas para dar apoio aos outros filhos. Desta forma, os demais membros são impossibilitados de participar diretamente da experiência que está apenas começando para a mãe.

\section{... mas minha família, depois que a T. ficou doente, ficou meio assim, né? Minha outra filha, a de nove anos ficou lá. Faz dias que não vejo mais ela. Ficou tudo meio separado, né?}

Prá quem nunca se separou, a distância que a gente tá praticamente há 3 meses, é muito tempo...ficar tanto tempo separado, é muito tempo...

Decidindo se entregar para salvar o filho, dá início a uma outra fase na vida da família, que coincide com a internação da criança. As famílias mostram que esse proces- 
so de internação da criança é doloroso para todos, representando uma interrupção no modo de viver até então, mas é um evento dramático, sobretudo, na vida da mãe acompanhante.

Eu tenho outro filhos mas agora minha preocupação é com ele. Eu vim, larguei tudo porque a única esperança é a cirurgia.

A gente chegou aqui e nem conhecia o pessoal que a gente está na casa deles hoje. A gente se encontrou na rodoviária pela cor da roupa que a gente tava usando e pelo bebe no colo, assim... ah, eu vou estar com tal roupa. A gente só tinha conversado uma única vez pelo telefone, foi uma conhecida da minha cunhada que vendo a gente naquele desespero conseguiu.

Uma nova trajetória é seguida pela família, especialmente pela mãe, que passa a viver em função do tratamento da criança. A hospitalização é o processo ao qual a mãe se entrega para estar com o filho. Ela acredita que ninguém cuida como ela mesma. Assim, inicia-se a segunda fase da experiência, que é explicitada pelo tema, VIVENDO UMA EXPERIÊNCIA SOLITÁRIA.

\section{Vivendo uma experiência solitária}

A mãe permanece tomando conta para ver se o filho está sendo bem cuidado. Observa como é recebido e acompanha os procedimentos, mesmo sendo difícil vê-lo sofrendo. Praticamente fica morando no hospital, não dispondo do conforto de sua casa. Sabe que o filho é uma criança com risco de vida e, portanto, só sai de seu lado para atender suas necessidades pessoais e, ainda assim, somente quando é substituída por outra pessoa de sua confiança. Se não tem com quem rodiziar o cuidado do filho, sai "rapidinho" quando a criança está dormindo.

Durante esse processo, a mãe, vivendo uma experiência solitária, fica atenta a tudo que acontece na unidade e busca informações com os outros acompanhantes, tentando prever o que poderá acontecer com seu filho. Vive em estado de alerta em relação à criança, isto é, sempre tomando conta e observando o que pode acontecer e é assim, desde o momento que eles chegam ao hospital.

Vim só eu e a menina para cá porque não cabia outra pessoa no carro. Fiquei sozinha.

Três meses sozinha... É demais... O tempo não passa. Você fica aqui, só esperando, só esperando... dia e noite.

Vivendo uma experiência solitária é como a mãe sentese quando se vê longe da família e, em especial, dos outros filhos, sem poder executar as tarefas que realizava até decidir acompanhar o tratamento da criança, rompendo a rotina familiar. Este sentimento é acentuado por não poder compartilhar a experiência com o marido. Abrindo mão de tudo para salvar o filho, faz com que ela se dê conta de que o mergulho no tratamento do filho tem um custo existencial alto, ou seja, a separação de aspectos importantes como os outros filhos que ficaram, a casa e a família. Longe da família, muitas vezes, sem poder expressar seus sentimentos e angústias com ninguém, sentindo-se desamparada e, absolutamente sozinha, sentindo falta do aconchego da família, a mãe começa a pensar no que poderia ajudá-la a passar por essa experiência.

\footnotetext{
... e os telefonemas que eu fui dando, aí vai aliviando, né?

Eu moro em Lins; foi assim que foi me aliviando....
}

Permanecendo ao lado da criança, ao mesmo tempo que fica olhando, ela vai procurando respostas para as inseguranças. Este é o movimento da mãe na busca de respostas do que pode vir a acontecer, a partir da comparação com outras crianças internadas. Comparar a situação em que se encontra o seu filho com as outras crianças, é uma estratégia utilizada na busca por uma causa para o acontecido. Examinar outros casos ajuda a mãe a elucidar suas dúvidas e a ter forças para seguir em frente.

Foi minhas colegas me dando força, me passando coisas positivas... que os filhos delas já estavam bem. Eu tive que fazer que nem elas... Ter fé que ia sair como os delas também.

Dentre todas as dificuldades que a mãe passa durante a jornada do tratamento da criança, ela refere-se ao momento da cirurgia como sendo o mais difícil. Temendo a Cirurgia, explica a fase na qual a criança já concluiu todos os exames pré-operatórios, apresenta peso adequado para realizar a cirurgia e está apenas aguardando vaga no centro-cirúrgico. Nesta fase, a mãe já teme por todas as complicações que podem advir da cirurgia e, sobretudo, teme a morte da criança. Permanece no hospital em uma morosidade de tempo, sem atividades para desenvolver, passando o tempo conversando com os outros familiares. É como se a mãe ficasse esperando a hora de mandar seu filho para um "veredicto final". As incertezas da escolha pelo procedimento cirúrgico acarretam muita angústia aos pais.

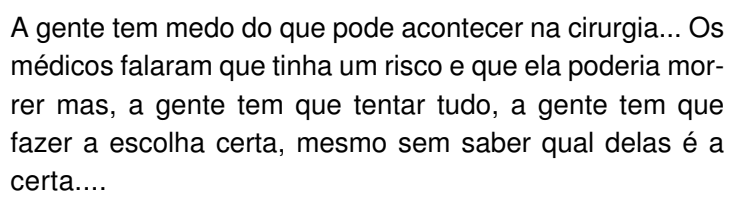

Conhecendo os riscos que o filho corre na cirurgia e vendo outros morrendo, o tratamento da criança é, finalmente, representado pelo temor das mães de perderem o filho, tendo medo do filho morrer. Diante de tudo que esta já passou, esperar a cirurgia também não é nada tranqüilo. Ela permanece ansiosa, aguardando a vez de seu filho, querendo que ele não tenha febre, para que não suspendam a cirurgia e para que tudo acabe bem. É uma situação aflitiva à mãe, pois após ter se decidido pela cirurgia, precisar aguardar o dia marcado é sempre uma espera apreensiva. 
Aí ficamos aguardando. Era pra fazer na outra quinta, mas chegou outra criança que tava com mais urgência que ele, aí encaminharam na frente.

No começo eu não pensei em desistir, mas quando foi chegando o dia mesmo assim para fazer a cirurgia, eu fiquei pensando: será que não é bom? Será que se fazer ele vai melhorar? Será que se desistir agora ele corre o risco pior?

Entregando a criança, é o momento que marca a parte mais difícil da experiência da mãe, enquanto vai Vivendo uma experiência solitária. Entregar o filho e saber que, a partir dali, a criança estará nas mãos de pessoas desconhecidas, mas das quais depende a vida do filho é um momento difícil; não mais lhe será possível voltar atrás na decisão de enviar a criança à cirurgia. Vivendo a possibilidade de vir a perder o filho é o momento da experiência familiar, quando ela se depara com a possibilidade de perder o filho por ter se decidido pela cirurgia. Viver a incerteza de rever o filho é bastante complicado à família que aguarda o término da cirurgia, tentando acreditar em um final feliz.

Que tava entregando o meu filho na mão de gente que não conhecia. Achava que não ia superar isso tudo, mas graças a Deus....

Porque é assim... como avisaram que a cirurgia era de risco eu ficava com medo de acontecer alguma coisa mais grave lá e eu não estar por perto.

A mãe, ficando confinada, precisa aguardar, sem nada poder fazer ou intervir. Nesta situação, a mãe apega-se às suas crenças; ela espera pelo término da cirurgia pensando, rezando, imaginando o que poderá estar acontecendo ou aguardando, ansiosamente, ser chamada para receber alguma notícia de alívio e consolo. A religião é a força que busca para ajudá-la a suportar passar pelas horas da cirurgia. Procura manter-se forte o tempo todo, porém, ao se vir de mãos atadas para ajudar o filho, entrega nas mãos de Deus, tendo muita fé de que vai dar certo.

Ficando confinada $a_{2}$ é representado pela insistência da mãe permanecer horas, aguardando por algum tipo de notícia, ainda que seja apenas a informação de que está tudo bem, mesmo que a cirurgia não tenha terminado. Isto permite à família um certo alívio e a esperança de poder continuar ansiando.

Aí ficou eu, meu marido e o padrinho dela. Nós ficamos lá embaixo... esperando. A gente nem conversava, não fazia nada, não. Só esperava.

Poder ter o filho de volta é a recompensa que a família tem por ter decidido-se pela cirurgia cardíaca da criança e ter passado por momentos tão difíceis em razão de sua escolha. Sentindo-se aliviados, é como a mãe sente-se ao receber a notícia do término do procedimento e saber que a criança sobreviveu. Neste momento, ela acredita ter feito a escolha certa. Ter superado o tempo da cirurgia faz com que acredite que o filho pode superar qualquer coisa dali para frente.
Saber que tinha acabado e que ele estava bem... Um alívio, não dá nem para explicar com palavras. Foi um alívio.

Tendo superado uma etapa, tem um significado de estar chegando ao fim, tanto para a mãe que começa a imaginar seu retorno, como para a família que aguarda a chegada dos que estão longe. Com o fim da cirurgia, as esperanças renovam-se, pois a família percebe que o filho é forte e conseguiu sobreviver. Então, os esforços agora são canalizados para aguardar a recuperação completa da criança e retomar a vida de antes e, especialmente, os cuidados diretos do filho.

Só corrigiram o problema, pois mais para frente ele vai precisar de um transplante.

Agora eu não sei como vai ser. Ele está só tomando os medicamentos por 14 dias; hoje tem 6 dias.

Logo após a cirurgia, a criança é encaminhada à UTI e por lá permanece até que esteja estável para, então poder ficar na internação pediátrica. A mãe deseja ficar todo o tempo que consegue perto de seu filho. Muitas acreditam que, estando a seu lado, podem impedir que qualquer coisa de ruim aconteça à criança. É uma forma de proteção materna, amparar o filho nesta situação e defendê-lo do ameaçador mundo hospitalar. Mas é acima de tudo, uma forma de manter a unidade familiar.

Para muitas famílias, a batalha não acaba aí; o filho terá necessidade de passar por novas cirurgias ou, então, continuar o tratamento em casa. Para isso, há necessidade de uma reorganização dos papéis sociais na unidade familiar; um planejamento no sentido de proteger a criança daqui para frente.

\section{CONCLUSÕES}

A experiência no modelo teórico Buscando preservar a integridade da unidade familiar $^{(5)}$, começa com a ruptura familiar quando a criança é retirada de seu convívio e internada na UTI. A família não se decide pela internação, mas, é comunicada da decisão médica. Na situação da cirurgia cardíaca do filho, a família está consciente de que os laços precisarão ser rompidos por um tempo indeterminado. Assim, decidindo pela cirurgia, permite que ela se prepare para a ruptura que terá de enfrentar, mas, é uma decisão que visa atingir o objetivo de PRESERVAR A INTEGRIDADE DA UNIDADE FAMILIAR.

Nesta experiência, um aspecto novo contribui para a ampliação do modelo teórico validado, que é a mãe VIVENDO UMA EXPERIÊNCIA SOLITÁRIA, quando no modelo de Bousso a experiência é vivida sempre pela família. Ainda que a mãe seja a pessoa mais presente no hospital, ela está sempre rodeada por familiares que telefonam, enviam presentes, encomendam preces e acompanham cada momento do estado da criança, dando força uns aos outros ${ }^{(5)}$. 
O final da cirurgia é caracterizado pela força da criança TENDO SUPERADO UMAETAPA. Neste momento, a criança é encaminhada à UTI. Nesta experiência, a mãe ressignifica sua crença de que a UTI é um lugar para morrer, para a crença de que a UTI pode ser a esperança de recuperação do filho. Isto é consequiência do conviver da mãe com a possibilidade de morte da criança durante o tempo cirúrgico e de acreditar que a criança superou uma etapa após ter sobrevivido à cirurgia cardíaca. Ainda assim, deste ponto para frente, o processo iguala-se ao apresentado por Bousso ${ }^{(5)}$, não permitindo que o referido modelo possa ser reduzido.

Assim, pela análise comparativa dos resultados dos dois estudos, foi possível validar o modelo teórico que tem como categoria central BUSCANDO PRESERVAR A INTEGRIDADE DA UNIDADE FAMILIAR e é capaz também de integrar categorias que compõe a experiência da família que aguarda pela cirurgia cardíaca do filho.

Este trabalho contribuiu ao ampliar a compreensão do significado da experiência da mãe que vive a hospitalização do filho, longe da família. Neste sentido, revelou a necessidade urgente de olharmos para a mãe ou o membro da família presente na situação como alguém que precisa de cuidado, solidariedade, apoio, sobretudo para não se sentir responsável por algum fato indesejável que venha a acontecer com o filho, como a morte ou até mesmo alguma seqüela, decorrente de sua decisão pela cirurgia.

Vale ressaltar que o estudo foi realizado apenas com famílias de crianças que sobreviveram à cirurgia. Assim, novos trabalhos devem ser conduzidos com o objetivo de melhor explorar as diferentes experiências decorrentes dos desdobramentos da cirurgia cardíaca da criança para a família.

Nosso entendimento sobre a experiência da família está começando. É necessário prosseguirem as investigações que nos mostrem mais e melhor como a família vivencia diferentes experiências, trazendo novos modelos teóricos que permitam à enfermeira apreender o que está se passando com a família, dando mais sentido às proposições diagnósticas e à suas intervenções.

\section{REFERÊNCIAS}

(1) Bousso RS, Rolim MA, Horta AL. Approach of the assistance to the hospitalizes child: until where does the family inclusion goes. In: Libro programa y resumen de la $4^{\mathrm{a}}$ Conferência Internacional de Enfermeria Familiar, nov. 11-14; Valvidia. Valdívia: Universidad Austral de Chile; 1997. [p. 192]

(2) Angelo M. Com a família em tempos difíceis: uma perspectiva de enfermagem [tese livre-docência]. São Paulo: Escola de Enfermagem da Universidade de São Paulo; 1997.

(3) Bousso RS. Family dynamics of children admitted to cardiology hospital: description of the significant categories. In: Libro programa y resumen de la $4^{\mathrm{a}}$ Conferência Internacional de Enfermeria Familiar, nov. 11-14; Valvídia. Valdívia: Universidad Austral de Chile; 1997. PO 68.

(4) Marques PM, Bousso RS. O impacto do diagnóstico para os pais da criança portadora de cardiopatia congênita [monografia] São Paulo: Escola de Enfermagem da USP; 1997.
(5) Bousso RS. Buscando preservar a integridade da unidade familiar: a família vivendo a experiência de ter um filho na UTI. Rev Esc Enferm USP. 2001;35(2):172-9.

(6) Morse JM. Qualitative verification: building evidence by extending basic findings. In: Morse JM, Swanson JM, Kuzel AJ, editors. The nature of qualitative evidence: London: Sage; 2001. p. 203-20.

(7) Chinn PL, Kramer MK. Replicating and validating empiric knowledge using research. In: Integrated knowledge development in nursing. $6^{\text {th }}$ ed. Missouri: Mosby; 2004. p. 121-43.

(8) Glaser BG, Strauss AL. The discovery of grounded theory. New York: Aldine; 1967. 